ORIGINAL ARTICLE

\title{
Risk of hypertension with multicystic kidney disease: a systematic review
}

\section{H Narchi}

See end of article for authors' affiliations

....................

Correspondence to: Dr H Narchi, Paediatric Department, Sandwell General Hospital, West Bromwich B71 4HJ, UK; hassibnarchi@hotmail.com

Accepted 1 May 2005 Published Online First 4 May 2005

\begin{abstract}
Background: Children with multicystic kidney disease (MCKD) are increasingly managed conservatively, and are followed up throughout childhood because of the risk of hypertension highlighted in some reports. With this risk still poorly defined, the strategy and the duration of follow up do not seem to be based on evidence.

Methods: Systematic review of the literature for all published cohort studies (prospective and retrospective) of children diagnosed to have unilateral MCKD and managed conservatively. Exclusion criteria were bilateral MCKD, and nephrectomy (not for hypertension) during the follow up period. For children with MCKD, the probability of developing hypertension during the follow up period was estimated.

Results: From 29 reviewed studies, six cases of hypertension developed in 1115 eligible children. The mean probability of a child with unilateral MCKD developing hypertension was therefore 5.4 per 1000 (95\% Cl estimated at 1.9 to 11.7 per 1000).

Conclusion: Although the risk of hypertension in MCKD is low, the results of this study do not allow firm recommendations on the frequency and duration of blood pressure measurement follow up for these children. Large prospective cohort studies with a very long duration of follow up are needed.
\end{abstract}

$\mathrm{H}$ ypertension has been reported in children with multicystic kidney disease (MCKD), even after involution, but the true incidence unknown. ${ }^{1-4}$ The suggested mechanism of hypertension is ischaemia induced renin secretion of in the juxtaglomerular apparatus of mature glomeruli and interlobular arteries in the scarred areas of the dysplastic kidney. ${ }^{5}$ Pronounced ectopic renin expression by macrophages may also be a contributing factor. ${ }^{7}$ More children with MCKD are being now diagnosed antenatally, with an estimated incidence of 1:4300 live births. ${ }^{8}$ In the absence of complications, they are increasingly managed conservatively, but because of the perceived long term risk of hypertension they are also followed up throughout childhood. ${ }^{8-12}$ With the risk of hypertension in these children still poorly defined, the strategy and the duration of follow up do not seem to be based on evidence. ${ }^{341314}$ In addition, even when the spontaneous involution (in approximately $40 \%$ of cases) is documented on ultrasound scan and most units cease imaging studies at that point, there may still be a risk of hypertension. ${ }^{415}$

More epidemiological information is needed to properly assess and quantify this risk for a scientifically robust and consistent planning of the surveillance strategy as well as to counsel the child and his/her parents. The prospective data collected by the American MCKD Registry was published in 1993 and did not show any case of hypertension in the reported 260 children, but no further data have been published since that time. ${ }^{12}$

We therefore undertook a literature search to try to estimate the epidemiology of hypertension in children with MCKD.

\section{METHODS}

\section{Study retrieval and selection strategies}

We undertook a systematic review of the literature for all published cohort studies (prospective and retrospective) of unselected children with unilateral MCKD, diagnosed antenatally or postnatally, using PubMed (from January 1966 to March 2005), Embase (from January 1974 to March
2005), and the Cochrane Library (2005, issue 1). Search strategy: "multicystic dysplastic kidney" [MeSH major topic, OR MeSH subheading, OR MesH term OR free text] AND ("cohort studies" OR "prospective studies" OR "retrospective studies" OR "follow-up studies" OR "incidence" OR "outcome" OR "complications" OR "hypertension"). Although "polycystic kidney diseases" were excluded, a MeSH and free text search for that definition was also been carried out in the search of a possible definition or misclassification bias with MCKD. The review was focused on published studies in peer reviewed journals and therefore specifically omitted data from the "grey" and unpublished literature, such as meetings or conferences abstracts, contacts with experts in the field, or data from previously published guidelines. The author examined each paper's title and abstract, the full paper when necessary, and also the reference lists of relevant studies to identify relevant articles, especially when pre-1966. The author decided which studies to be included in the final review.

\section{Eligibility}

From the retrieved studies, we only analysed the children who were managed conservatively and followed up for hypertension as an outcome. Only persistent hypertension was considered in the outcome as we excluded from the definition transient hypertension, sometimes associated with acute pyelonephritis.

\section{Case definition}

There was no uniform or standardised definition of hypertension between the reports.

\section{Exclusion criteria}

Polycystic kidney disease was excluded from analysis. As bilateral MCKD is invariably lethal, we excluded those infants from the study. ${ }^{16}$ We also excluded infants who were diagnosed antenatally but were stillborn, as well as those who had involution of the MCKD at birth as they were not followed up for hypertension later in life. In addition, we 
excluded those who underwent nephrectomy (not for hypertension) during the follow up period. Case reports or selected studies of children with MCKD with hypertension were not included as the denominator of all children with MCKD was not known in those studies.

\section{Consolidation of all reported data}

We calculated the total number of children with conservatively managed unilateral MCKD, and the number and percentage of children developing hypertension on last follow up.

\section{Statistical analysis}

As the follow up time for each individual child was not available, the accurate incidence rate of hypertension could not be computed. With the variable duration of follow up in the studies and the fact that the outcome was reported as a group (number of children who developed hypertension within each cohort) without specific results on individual cases (in whom and when hypertension developed), actuarial or "survival"-type data analysis was not possible. For the same reasons, it was not possible to use multivariate analysis such as logistic regression or proportional hazard methods to take into account the role of the many potential confounders. The only available mode of analysis was therefore simple aggregation of the data according to the number (or proportion) of children with hypertension given in the studies. We therefore estimated for children with MCKD the probability of developing hypertension during the follow up period, with $95 \%$ confidence intervals (95\% CI) using the Poisson distribution for rare and independent events. With the unavailability of the age at which hypertension was diagnosed in most of these reports, the probability of developing that outcome in relation to specific age bands or follow up duration could not be computed either.

\section{RESULTS}

\section{Study selection}

The "MCKD" search yielded 284 studies and the "polycystic kidney diseases" 4001 articles, of which only a handful referred to MCKD and had all already been identified in the initial "MCKD" search. From the 284 reports, 255 were not eligible for inclusion (87 case reports, 76 antenatal studies, and the rest with a combination of several exclusion criteria).

\section{Validity criteria}

The remaining 29 studies fulfilled the inclusion criteria fully: all were unselected cohorts of children and included a follow up period with hypertension defined as an outcome. The level of evidence of each individual study was estimated at level III.2. There was no selection bias in the reporting, nor attrition bias as, although the duration of follow up between patients was variable in the different reports, it did not differ systematically between the reports where hypertension was found or not. In addition, the losses to follow up were few and not systematically different among the studies. No performance or detection bias were identified in the studies as the follow up for and the reporting of hypertension did not differ systematically among the reports.

\section{Overview of the results}

Those 29 eligible studies were analysed and their results are summarised in table 1. The geographical origin of these reports were: UK (5), the USA (5), Japan (5), Germany (3), Italy (2), Spain (2), Brazil (2), Canada (1), Austria (1), Finland (1), the Czech republic (1), and Israel (1). The majority of these studies (15) are very recent (after 2000); 12 reports originated between 1990 and 1999, and only two between 1980 and 1989.

There were 1536 children included in these reports. The study exclusion criteria identified 421 children $(27.4 \%)$ who were excluded from the analysis (bilateral disease, stillbirths,

\begin{tabular}{|c|c|c|c|}
\hline Study & $\begin{array}{l}\text { No. of children } \\
\text { (antenatal diagnosis) }\end{array}$ & $\begin{array}{l}\text { Follow up in years; } \\
\text { mean (range) }\end{array}$ & $\begin{array}{l}\text { No. of children with } \\
\text { hypertension }\end{array}$ \\
\hline Al Khaldi et all ${ }^{6}$ & $30(30)$ & & 0 \\
\hline Aubertin ef $a l^{88}$ & $54(54)$ & & 0 \\
\hline Belk et $a f^{19}$ & $29(29)$ & & 0 \\
\hline Cigna et a ${ }^{\circ}$ & $16(0)$ & & 0 \\
\hline Ekoldt et $a^{P^{1}}$ & $42(42)$ & $3(0.3-6)$ & 2 \\
\hline Feldenberg et $a^{P^{2}}$ & $28(28)$ & & 0 \\
\hline Gordon et $a^{\beta}$ & $23(23)$ & & 0 \\
\hline John et $a^{p^{3}}$ & $27(27)$ & $4.9(1-11.6)$ & 0 \\
\hline Kaneyama ef $a f^{24}$ & 30 & 5.3 & 0 \\
\hline Kessler et $a^{p^{5}}$ & $23(18)$ & & 0 \\
\hline Kuwertz-Broeking et all & 75 & $4(1-11)$ & 1 \\
\hline Martin et $a^{P^{6}}$ & 15 & & 0 \\
\hline Matsumoto ef $a p^{27}$ & $44(41)$ & $4.5(1.4-9)$ & 0 \\
\hline Miller et af ${ }^{8}$ & 75 & 4.4 & 0 \\
\hline Okada et ap $p^{p}$ & $10(10)$ & $4(1.5-100)$ & 0 \\
\hline Oliveira et ap & $20(20)$ & $3(0.5-8)$ & 0 \\
\hline Orejas et $a^{\beta 0}$ & 12 & 3 & 0 \\
\hline Orikasa et $a^{\beta 1}$ & 18 & $(0.5-5)$ & 0 \\
\hline Perez et $a^{\beta 2}$ & 49 & 4 & 0 \\
\hline Rabelo et $a^{\beta^{3}}$ & $43(43)$ & $4(1-13)$ & 2 \\
\hline Rickwood et a ${ }^{\beta 4}$ & 33 & $3(1.2-6)$ & 0 \\
\hline Ring et $a^{\beta 5}$ & $6(6)$ & $(0.8-1.5)$ & 0 \\
\hline Seeman et $a^{\beta 6}$ & $18(18)$ & & 0 \\
\hline Sukthankar et a ${ }^{\beta 7}$ & $66(66)$ & 5 & 0 \\
\hline Tilemis et $a l^{14}$ & $20(20)$ & $(0.8-6)$ & 0 \\
\hline Tohda et $a^{\beta 8}$ & $14(14)$ & & 0 \\
\hline Vinocur et al ${ }^{10}$ & $19(19)$ & $3(0.2-9)$ & 1 \\
\hline Wacksman et al ${ }^{12}$ & $260(260)$ & & 0 \\
\hline Ylinen et $a l^{\beta 9}$ & 16 & 4 & 0 \\
\hline Total $=29$ studies & $1115(801)$ & & 6 \\
\hline
\end{tabular}


What is already known on this topic

- Children with MCKD are followed up throughout childhood because of the risk of hypertension, although this risk is poorly defined

- The duration of follow up for blood pressure surveillance is widely variable, and not based on solid evidence

nephrectomy but not for hypertension). The remaining eligible 1115 children with unilateral MCKD who were treated conservatively and followed up were included for review (table 1). At least 801 of those children $(72 \%)$ were diagnosed antenatally.

The earliest patients were followed up since $1975 .{ }^{10}$ Fourteen studies did not report the duration of follow up, while the mean duration of follow up in the other 15 studies ranged from 3 to 5.3 years, with an average of 3.8 years and a maximum of 13 years of follow up.

Throughout the follow up period, only six of the 1115 children developed hypertension (excluding four children with transient hypertension). ${ }^{17}$ The mean probability of these children developing hypertension (Poisson distributed counts) was therefore 5.4 per 1000 children with MCKD, with 95\% confidence intervals of 1.9 (less than 2 per 1000 children) to 11.7 (less than 12 per 1000 children).

\section{DISCUSSION}

The results of this systematic review are reassuring, showing that the mean probability of a child with unilateral MCKD developing hypertension is 5.4 per 1000 (95\% CI 1.93 per 1000 to 11.7 per 1000). This confirms the findings and recommendations of other reports, including that of the American Multicystic Kidney Registry. ${ }^{12} 1340$

This review had a number of inherent weaknesses. The 29 studies were not homogeneous. They were reported over a span of 27 years. With antenatal ultrasonography not available in the earlier years and its diagnostic accuracy progressively improving since its early use, it is likely that selection bias has occurred. In addition, antenatally diagnosed cases of MCKD (with variable degree of accuracy throughout the study period) were grouped together with other postnatally diagnosed cases (such as children with an abdominal mass), although the natural history and the prognosis for hypertension might not be similar between these two groups. Another weakness in this systematic review is that the duration of follow up varied widely between the 29 studies. Making a diagnosis of hypertension in children is not always easy, as obtaining reliable reproducible blood pressure readings in fractious infants is very difficult. As there was no uniform or standardised definition of hypertension between the reports (such as blood pressure reading above the 95th centile for both age and height on repeated occasions using an appropriately sized cuff with the patient in the resting state), an inherent risk of misclassification outcome bias remains possible. Without a knowledge of the age when the hypertension was diagnosed, calculation of hypertension risk by age band is not possible, not enabling therefore an estimation of the duration of surveillance for that complication in children with MCKD. Another inherent limitation to the study was that the available data in the reports precluded any actuarial or "survival"-type data analysis, or the use of multivariate analysis such as logistic regression or proportional hazard methods to take into account the role of the many potential confounders.
What this study adds

- The results of this systematic review of cohorts including 1115 children show that the mean probability of a child with unilateral MCKD developing hypertension is 5.4 per 1000

- Although reassuring, the results of this study do not allow firm recommendations on the frequency and duration of blood pressure measurement follow up for these children

Publication bias and reporting bias may also have occurred, as only few studies have looked at and reported outcomes of MCKD in a systematic manner, in comparison to virtually all the cases of hypertension associated with MCKD being isolated case reports. As obviously many more series of children with MCKD have never been reported, the true number and proportion of children with MCKD who did not develop hypertension is likely to be even higher, making the estimated maximum incidence rate of hypertension in MCKD even lower than the results of this study. As it is likely that a significant percentage of unilateral renal agenesis cases are in fact MCKD which involute, the true incidence of MCKD is likely to be even higher than currently reported, resulting in an even lower risk of hypertension than theoretically calculated. ${ }^{15} 41$

The precision estimate of this risk could be refined further. While further information from the American registry would be very helpful, a national, or a European registry for children with MCKD needs to be developed, with systematic and uniform prospective long term follow up of affected children, including those where MCKD involutes. Further breakdown of cases between those diagnosed antenatally and those diagnosed later may also clarify any differences in the natural history or prognosis for hypertension between these two subgroups. Such long term cohort studies are likely to be difficult: with hypertension being relatively rare, a very large number of children with MCKD will need to be prospectively followed up for a very long period, well into adulthood, with the inherent risk of loss to follow up.

Of interest is that the calculated risk of hypertension with MCKD (5.4 per 1000) appears to be lower than the risk of hypertension in the general paediatric population, estimated to be $1-4.5 \%$ in children between the age of 4 years and adolescence. ${ }^{42-44}$ This is a surprising finding and may have several explanations. The definition for hypertension was not well defined or standardised in the reports analysed in the current study, unlike the prospective studies undertaken recently in the general paediatric population, possibly resulting in a misclassification bias. Furthermore, the incidence of hypertension with MCKD in older children is not well known as the longest follow up in the studies reported in this analysis was 13 years only, while the prospective studies in the general population included older children up to adolescence, making any comparison between these two groups unrealistic. Only long term follow up studies of cohorts with MCKD could establish if that incidence increases with age and could compare that risk with the incidence of hypertension in the general population. Despite these drawbacks, although it may not be lower, it is reassuring that the risk of hypertension with MCKD does not seem to be higher than the risk in the general paediatric population.

Although the risk of hypertension in such children was found to be low, the occurrence of late onset of hypertension secondary to hyperperfusion injury of the remaining kidney 
remains theoretically possible. Although this risk, if it does indeed exist, can only be evaluated by undertaking large cohort studies followed up for decades, it justifies in the meantime the need for ongoing blood pressure follow up for these children.

With more children with MCKD being now diagnosed antenatally, with an estimated incidence of 1:4300 live births, and with most being managed conservatively, the resource implications to follow them up for potential complications, including hypertension, are considerable. ${ }^{8}$ Although it is reassuring to realise that the risk of hypertension in MCKD is low, the results of this study do not allow firm recommendations on the frequency and duration of blood pressure measurement follow up for these children. More robust risk estimates with risk stratification by age bands are needed, and can only be achieved through large prospective cohort studies with a very long duration of follow up. Such studies would also be able to provide information on whether involution of the affected kidney modifies such a risk.

Competing interests: none

\section{REFERENCES}

1 Chen YH, Stapleton FB, Roy S III, et al. Neonatal hypertension from a unilateral multicystic dysplastic kidney. J Urol 1985;133:664-5.

2 Snodgrass WT. Hypertension associated with multicystic dysplastic kidney in children. J Urol 2000;164:472-3.

3 Susskind MR, Kim KS, King LR. Hypertension and multicystic kidney. Urology 1989;34:362-6.

4 Webb NJ, Lewis MA, Bruce J, et al. Unilateral multicystic dysplastic kidney: the case for nephrectomy. Arch Dis Child 1997:76:31-4.

5 Worck RH, Ibsen $\mathrm{H}$, Andersen $\mathrm{CB}$, et al. The etiology of hypertension in nonrenovascular unilateral renal disease-two cases of renin induced hypertension in congenital renal dysplasia. Blood Press 1995;4:113-16.

6 Konda $\mathrm{R}$, Sato $\mathrm{H}$, lto $\mathrm{S}$, et al. Renin containing cells are present predominantly in scarred areas but not in dysplastic regions in multicystic dysplastic kidney. J Urol 2001;166:1910-14.

7 Liapis H, Doshi RH, Watson MA, et al. Reduced renin expression and altered gene transcript profiles in multicystic dysplastic kidneys. J Urol 2002; 168:1816-20.

8 Gordon AC, Thomas DF, Arthur RJ, et al. Multicystic dysplastic kidney: is nephrectomy still appropriate? J Urol 1988;140:1231-4.

9 Oliveira EA, Diniz JS, Vilasboas AS, et al. Multicystic dysplastic kidney detected by fetal sonography: conservative management and follow-up. Pediatr Surg Int 2001;17:54-7.

10 Vinocur L, Slovis TL, Perlmutter AD, et al. Follow-up studies of multicystic dysplastic kidneys. Radiology 1988;167:311-15.

11 Strife JL, Souza AS, Kirks DR, et al. Multicystic dysplastic kidney in children US follow-up. Radiology 1993;186:785-8.

12 Wacksman J, Phipps L. Report of the Multicystic Kidney Registry: preliminary findings. J Urol 1993;150:1870-2.

13 Watson AR. Hypertension and multicystic dysplastic kidney. Pediatr Nephrol 2003; 18:1077.

14 Tilemis S, Savanelli A, Baltogiannis D, et al. Is the risk of hypertension an indication for prophylactic nephrectomy in patients with unilateral multicystic dysplastic kidney? Scand J Urol Nephrol 2003;37:429-32.

15 Pedicelli G, Jequier S, Bowen AD, et al. Multicystic dysplastic kidneys: spontaneous regression demonstrated with US. Radiology 1986;161:23-6.

16 al Khaldi N, Watson AR, Zuccollo J, et al. Outcome of antenatally detected cystic dysplastic kidney disease. Arch Dis Child 1994;70:520-2.

17 Kuwertz-Broeking E, Brinkmann OA, Von Lengerke HJ, et al. Unilateral multicystic dysplastic kidney: experience in children. BJU Int 2004;93:388-92.

18 Aubertin G, Cripps S, Coleman G, et al. Prenatal diagnosis of apparently isolated unilateral multicystic kidney: implications for counselling and management. Prenat Diagn 2002;22:388-94.
19 Belk RA, Thomas DF, Mueller RF, et al. A family study and the natural history of prenatally detected unilateral multicystic dysplastic kidney. J Urol 2002;167:666-9

20 Cigna RM, Vella M, Rosella V, et al. [Conservative treatment of dysplastic multicystic kidney]. Minerva Pediatr 1997;49:193-6.

21 Eckoldt F, Woderich R, Wolke S, et al. Follow-up of unilateral multicystic kidney dysplasia after prenatal diagnosis. J Matern Fetal Neonatal Med 2003;14:177-86.

22 Feldenberg LR, Siegel NJ. Clinical course and outcome for children with multicystic dysplastic kidneys. Pediatr Nephrol 2000;14:1098-101.

23 John U, Rudnik-Schoneborn S, Zerres K, et al. Kidney growth and renal function in unilateral multicystic dysplastic kidney disease. Pediatr Nephrol 1998; 12:567-71.

24 Kaneyama K, Yamataka A, Satake S, et al. Associated urologic anomalies in children with solitary kidney. J Pediatr Surg 2004;39:85-7.

25 Kessler OJ, Ziv N, Livne PM, et al. Involution rate of multicystic renal dysplasia. Pediatrics 1998;102:e73

26 Martin JA, Piro C, Sanchis L, et al. [ls it necessary to remove polycystic kidneys?]. Cir Pediatr 1990;3:53-5.

27 Matsumoto F, Shimada K, Hosokawa S, et al. [Outcome of neonates born with unilateral multicystic dysplastic kidneys]. Nippon Hinyokika Gakkai Zasshi 2001;92:615-18

28 Miller DC, Rumohr JA, Dunn RL, et al. What is the fate of the refluxing contralateral kidney in children with multicystic dysplastic kidney? J Urol 2004; 172:1630-4

29 Okada T, Yoshida H, Matsunaga T, et al. Multicystic dysplastic kidney detected by prenatal ultrasonography: natural history and conservative management. Pediatr Surg Int 2003;19:207-10.

30 Orejas G, Malaga S, Santos F, et al. Multicystic dysplastic kidney: absence of complications in patients treated conservatively. Child Nephrol Urol 1992;12:35-9.

31 Orikasa K, Konda R, Sakai K, et al. [Eighteen cases of multicystic kidney: natural history and renal function of the contralateral kidney]. Nippon Hinyokika Gakkai Zasshi 1996;87:780-8.

32 Perez LM, Naidu SI, Joseph DB. Outcome and cost analysis of operative versus nonoperative management of neonatal multicystic dysplastic kidneys. J Urol 1998; 160:1207-11.

33 Rabelo EA, Oliveira EA, Diniz JS, et al. Natural history of multicystic kidney conservatively managed: a prospective study. Pediatr Nephrol 2004; 19:1102-7.

34 Rickwood AM, Anderson PA, Williams MP. Multicystic renal dysplasia detected by prenatal ultrasonography. Natural history and results of conservative management. Br J Urol 1992;69:538-40.

35 Ring $E$, Petritsch $P$, Riccabona $M$, et al. [Which therapy is necessary for prenatally diagnosed multicystic kidney dysplasia?]. Klin Padiatr 1993;205:150-2.

36 Seeman T, John U, Blahova K, et al. Ambulatory blood pressure monitoring in children with unilateral multicystic dysplastic kidney. Eur J Pediatr 2001;160:78-83.

37 Sukthankar S, Watson AR. Unilateral multicystic dysplastic kidney disease: defining the natural history. Anglia Paediatric Nephrourology Group. Acto Paediatr 2000;89:811-13.

38 Tohda A, Hosokawa S, Shimada K. [Management of multicystic dysplastic kidney detected in perinatal periods]. Nippon Hinyokika Gakkai Zasshi 1992;83:1628-32.

39 Ylinen $\mathbf{E}$, Ahonen S, Ala-Houhala $M$, et al. Nephrectomy for multicystic dysplastic kidney: if and when? Urology 2004;63:768-71.

40 Thomas DF, Fitzpatrick MM. Unilateral multicystic dysplastic kidney. Arch Dis Child 1997;77:368-9

41 Avni EF, Thoua Y, Lalmand B, et al. Multicystic dysplastic kidney: evolving concepts. In utero diagnosis and post-natal follow-up by ultrasound. Ann Radiol (Paris) 1986;29:663-8

42 Sorof JM, Lai D, Turner J, et al. Overweight, ethnicity, and the prevalence of hypertension in school-aged children. Pediatrics 2004;113:475-82.

43 Adrogue HE, Sinaiko AR. Prevalence of hypertension in junior high schoolaged children: effect of new recommendations in the 1996 Updated Task Force Report. Am J Hypertens 2001;14:412-14.

44 Munteanu D, Schioiu-Costache L, Nita I, et al. Prevalence of arterial hypertension in a collectivity of adolescents. Med Interne 1990;28:241-3. 